\title{
Práticas formativas na educação profissional: a emergência de uma didática específica?
}

\section{Formative practices in professional education: the emergency of a specific didactics?}

\section{Prácticas formativas em la educación professional: ¿lá emergência de una didáctica específica?}

\author{
Marilandi Maria Mascarello Vieira* \\ Maria Cristina Pansera de Araújo** \\ Josimar de Aparecido Vieira**
}

\section{Resumo}

Este trabalho tem por objeto a discussão acerca da existência de uma didática específica para a Educação Profissional e seu propósito central foi identificar como autores referenciais dessa área, dentre eles Kuenzer (1998, 2010), Machado (2008, 2010), Ramos (2011, 2014), Barato (2004, 2008), Araujo (2008, 2010) Gruber, Allain; Wollinger (2017) e Wollinger; Allain; Gruber, (2017) compreendem essa temática. A abordagem metodológica foi orientada pela pesquisa qualitativa do tipo bibliográfica, analisando os trabalhos dos autores na tentativa de responder a seguinte indagação: Como os autores referenciais da área apresentam a discussão acerca da didática para a educação profissional e como têm caracterizado as práticas formativas que nela são desenvolvidas em suas produções acadêmicas? Os resultados indicam que, como expresso na primeira seção, as categorias gerais da didática, como as finalidades, os conteúdos, a metodologia e a avaliação são objetos de análise nos trabalhos, porém, embora se advogue a necessidade da elaboração de uma didática própria, posição defendida por autores analisados na segunda seção do trabalho, a educação profissional não conta com conhecimentos suficientes sobre os processos de produção e de aprendizagem dos saberes técnicos, especialmente dos processos operacionais, que subsidiem a formulação de proposições para elaboração dessa didática específica.

Palavras-chave: Educação Profissional. Didática. Cursos técnicos.

Recebido em 29/05/2019 - Aprovado em 30/09/2019

http://dx.doi.org/10.5335/rep.v27i1.10581

Doutora em Educação nas Ciências pela Universidade Regional do Noroeste do Estado do Rio Grande do Sul (UNIJUI, Brasil). Professora do Programa de Mestrado em Educação da Unochapecó. ORCID: https://orcid.org/0000-00025531-9946. E-mail: mariland@unochapeco.edu.br

* Doutora em Genética e Biologia Molecular pela Universidade Federal do Rio Grande do Sul (Ufrgs, Brasil). Professora pesquisadora do Programa de Pós-Graduação em Educação nas Ciências na Universidade Regional do Noroeste do Estado do Rio Grande do Sul (Unijui, Brasil). ORCID http://orcid.org/0000-0002-2380-6934. E-mail: pansera@unijui. edu.br

*** Doutor em Educação pela Pontifícia Universidade Católica do Rio Grande do Sul (PUCRS, Brasil). Professor do Instituto Federal de Educação, Ciência e Tecnologia do Rio Grande do Sul, campus Sertão. (IFRS, Brasil). ORCID https://orcid. org/0000-0003-3156-8590. E-mail: josimar.vieira@sertao.ifrs.edu.br 


\section{Abstract}

This paper aims to discuss the existence of a specific didactics for Professional Education and its main purpose was to identify how reference authors of this area, among them Kuenzer (1998, 2010), Machado (2008, 2010), Ramos (2011, 2014), Cheap (2004, 2008), Araujo (2008, 2010) Gruber, Allain; Wollinger (2017) and Wollinger; Allain; Gruber, (2017) understand this theme. The methodological approach was guided by qualitative research of the bibliographic type, analyzing the works of the authors in an attempt to answer the following question: How the referential authors of the area present the discussion about the didactics for professional education and how they have characterized the formative practices that in it are developed in your academic productions? The results indicate that, as expressed in the first section, the general categories of didactics, such as the purposes, the contents, the methodology and the evaluation are objects of analysis in the works. However, although the need for the elaboration of its own didactics is advocated, position defended by authors analyzed in the second section of the paper, vocational education does not have sufficient knowledge about the processes of production and learning of technical knowledge, especially the operational processes, which support the formulation of propositions for the elaboration of this specific didactics.

Keywords: Professional Education. Didactics. Technical courses.

\section{Resumen}

Este documento tiene como objetivo discutir la existencia de una didáctica específica para la Educación Profesional. Su objetivo principal es identificar cómo autores de referencia de esta área, entre ellos Kuenzer (1998, 2010), Machado (2008, 2010), Ramos (2011, 2014), Barato (2004, 2008), Araujo (2008, 2010) Gruber, Allain; Wollinger (2017) y Wollinger; Allain Gruber, (2017) entienden este tema. El enfoque metodológico fue guiado por la metodología cualitativa del tipo bibliográfico, analizando los trabajos de los autores e intentando responder la siguiente pregunta: ¿Cómo los autores-referencia del área presentan la discusión sobre las didácticas para la educación profesional y cómo han caracterizado estas prácticas formativas en sus producciones académicas? Los resultados indican que, como se expresó en la primera sección, las categorías generales de didáctica, como los propósitos, los contenidos, la metodología y la evaluación son objetos de análisis en los trabajos. Sin embargo, aunque se aboga por la necesidad de elaborar sus propias didácticas, posición defendida por los autores analizados en la segunda sección del artículo, la educación profesional no desarrolla conocimientos suficientes sobre los procesos de producción y aprendizaje de saberes técnicos, especialmente los procesos operativos, que apoyan la formulación de propuestas para la elaboración de esta didáctica específica.

Palabras clave: Educación profesional. Didáctica Cursos técnicos.

\section{Introdução}

O uso de expressões ligadas à didática da/na educação profissional ou a metodologia de ensino são frequentes em vários âmbitos: intitulam cursos de formação continuada, são objeto de série de livros e constituem o currículo de cursos de especialização destinados a professores dessa modalidade de ensino. Além disso, as práticas educativas da educação profissional têm constituído pauta de trabalhos acadêmicos especialmente a partir de 2008, com a criação dos Institutos Federais de Educação, Ciência e Tecnologia - Ifes e consequente expansão do oferecimento de cursos de educação profissional. 
Essas referências indicam que se busca delinear procedimentos de ensino para essa modalidade devido às suas características distintivas: objeto de ensino, formas de organização, modalidades de oferta dos cursos e perfil dos estudantes e professores. Se ela é peculiar, a prática educativa que nela se efetiva também é diferenciada.

Em decorrência disso, este trabalho trata da emergência das discussões sobre o tema, circunscrito pela seguinte questão: Como os autores referenciais da área apresentam a discussão acerca da didática para a educação profissional e como têm caracterizado, em suas produções acadêmicas, as práticas formativas que nela são desenvolvidas?

Para lançar luzes sobre essa indagação, empregou-se a pesquisa qualitativa de natureza interpretativa por meio de revisão bibliográfica de produções de autores referenciais na educação profissional, como Kuenzer (1998, 2010), Machado (2008, 2010), Ramos (2011, 2014), Barato (2004, 2008), Araujo (2008, 2010) Gruber, Allain; Wollinger (2017) e Wollinger; Allain; Gruber, (2017) com a intenção de identificar pressupostos metodológicos que auxiliam na educação dos trabalhadores. A opção pelos autores citados deve-se ao fato de serem referências na área da educação profissional, sendo que a maioria deles tem uma vasta produção acadêmica sobre educação profissional, abordando suas diferentes facetas e, dentre elas, a preocupação com a organização do ensino.

Assim, para apresentar o presente trabalho, optou-se por uma estrutura textual organizadas em duas seções: a primeira parte, escrita a partir das produções de Kuenzer $(1998,2010)$ e Machado $(2008,2010)$, trata das categorias gerais que constituem a didática articuladas às práticas formativas da educação profissional $\mathrm{e}$ a segunda seção aborda como os autores apresentam a discussão acerca da didática para a educação profissional e como têm caracterizado as práticas formativas que nela são desenvolvidas em suas produções acadêmicas. Por fim, apresenta-se as considerações finais.

\section{Categorias gerais da didática na educação profissional}

Antes de adentrar no tema de abordagem do presente trabalho, impende explicitar o que se compreende por didática e por educação profissional. Em relação ao primeiro vocábulo, utilizamo-nos das reflexões de Pimenta (2003, p. 51) que conceitua a didática como a área da pedagogia que "investiga os fundamentos, as condições e os modos de realizar a educação, através do ensino”, e de Libâneo 
(1994, p. 16) que a caracteriza como "[...] uma disciplina que estuda os objetivos, os conteúdos, os meios e as condições do processo de ensino tendo em vista finalidades educacionais, que são sempre sociais".

Em relação à educação profissional, tomamos como referência Ferreti (2010, p. 1) que afirma que o termo educação profissional "refere-se aos processos educativos que têm por finalidade desenvolver formação teórica, técnica e operacional que habilite o indivíduo ao exercício profissional de uma atividade produtiva" (grifos nossos). O autor faz referência ao conceito de Militão (2000, p. 133 apud Ferreti, 2010, p. 1), que estabelece diferenciação entre as expressões educação profissional e formação profissional, pois essa última enfatiza o "saber fazer" enquanto a primeira valoriza, em tese, "a formação integral do profissional", o que reflete diferentes concepções acerca da sua função na sociedade atual.

Demarcados os conceitos fundamentais do trabalho, situamos a discussão sobre a existência ou a necessidade de elaboração de uma didática específica para a educação profissional, tema de pesquisa de Barato (2004, 2008), Ramos (2014), Araujo (2010), Gruber; Allain; Wollinger (2017) e Wollinger; Allain; Gruber (2017). Entretanto, outros autores ligados à educação profissional têm contribuído nesse sentido, explicitando elementos centrais da didática advindos das pesquisas que realizam no campo da educação e trabalho, como é o caso de $\operatorname{Kuenzer~}(1998,2010)$ e de Machado $(2008,2010)$ que apontam categorias gerais da didática que podem contribuir para o esclarecimento do tema.

As pesquisas de Kuenzer, em sua maioria, tratam de temas como as mudanças ocorridas no mundo do trabalho na transição da base de produção do modelo taylorista/fordista para o novo paradigma tecnológico, o regime de acumulação flexível, ou seja, a passagem da base eletromecânica para a base microeletrônica, analisando as articulações entre conhecimentos científicos e práticas laborais. Em seus trabalhos a autora procura estabelecer a relação entre esse cenário e o trabalho pedagógico, enfocando as relações de trabalho, conhecimento e educação no contexto da educação profissional, como podemos verificar em Kuenzer $(2003,2007,2004)$ que analisaremos a seguir a título de exemplificação.

Embora Kuenzer não faça referências a uma pedagogia/didática ou metodologia da educação profissional, dos resultados das suas pesquisas emergem princípios didáticos que ajudam a direcionar e organizar o trabalho docente na educação profissional, como ilustra o excerto transcrito a seguir: 
Embora, no limite, esta competência só vá ser desenvolvida pelo aluno no transcurso da prática laboral, não será possível o professor mediar aprendizagens significativas apenas no plano teórico; ele precisará organizar situações de aprendizagem em que o aluno articule os conhecimentos à prática laboral, desenvolvendo sua capacidade de análise, síntese, diagnóstico e solução de problemas. Isto não será possível se o docente não articular conhecimento científico e conhecimento tácito (KUENZER, 2010, p. 509.)

Outrossim, Kuenzer (1998), faz referência a uma "nova pedagogia do trabalho", que se desenvolve no âmbito das forças sociais e produtivas determinadas pelo mundo do trabalho e que, segundo a autora, auxiliam a compreensão acerca do que denominou "nova pedagogia escolar". A autora sintetiza os resultados das pesquisas analisando categorias fundantes dessa nova pedagogia - os conteúdos, as formas metodológicas, os espaços e atores educativos e as novas formas de controle -, que, em última análise, constituem as categorias gerais da didática.

Em relação aos conteúdos, Kuenzer (1998) afirma que não é necessária a inclusão de novos conhecimentos para a formação da classe trabalhadora, mas a democratização do saber socialmente produzido, transformado em saber escolar ${ }^{1}$. Ela sintetiza:

Os conteúdos são os mesmos: a forma de selecioná-los, organizá-los e trabalhá-los é que é diferenciada, uma vez que os tratamentos fragmentados por área do conhecimento e que tomam a memorização como habilidade fundamental, típicos do taylorismo/fordismo, estão superados (p. 39).

[...] as transformações no mundo do trabalho exigem, mais do que conhecimentos e habilidades demandadas por ocupações específicas, conhecimentos básicos, tanto no plano dos instrumentos necessários para o domínio da ciência, da cultura e das formas de comunicação, como no plano dos conhecimentos científicos e tecnológicos presentes no mundo do trabalho e das relações sociais contemporâneas (p. 36).

Relacionado a essa exigência no tratamento do conteúdo, Kuenzer (1998) ressalta a importância da transformação das formas metodológicas de ensino que, em linhas gerais, superem a ênfase na memorização de conteúdos, privilegiando o desenvolvimento de habilidades cognitivas, tais como "[...] localizar informações, trabalhar produtiva e criativamente com elas na construção de soluções para problemas postos pela dinâmica da prática social e produtiva" (KUENZER, 1998, p. 40).

Nessa direção, o papel do professor e da escola é abordado quando trata dos espaços e atores educativos e afirma que é o engenheiro o novo pedagogo do processo pedagógico que ocorre no espaço da fábrica. Que implicações isso traz para o professor e a sala de aula? Kuenzer (1998) defende a necessidade de a escola articular-se com o lócus de produção: o mundo das relações sociais e produtivas. Ela 
afirma que o novo papel do professor é fazer a mediação entre os alunos e a ciência na práxis social e produtiva, gerenciando, portanto, o processo de aprender, que não ocorre mais no âmbito individual, "[...] mas por meio de relações que são sociais e, portanto, articulam as dimensões individual e coletiva, subjetiva e objetiva, teórica e prática, que caracteriza o trabalho humano enquanto categoria fundante dos processos de produção do conhecimento" (KUENZER, 1998, p. 41).

Quanto às formas de controle, Kuenzer (1998) concluiu que essa foi a dimensão que mais sofreu alteração no espaço produtivo e a nova pedagogia do trabalho visa ao "desenvolvimento de uma nova subjetividade, que viabilize a internalização do processo de controle, o estabelecimento do controle inter-pares e a apropriação dos conhecimentos necessários para que esta participação ativa se realize" (KUENZER, 1998, p. 41). Assim, a autora defende que a nova pedagogia escolar invista no contrário, ou seja, “[...] na formação da consciência crítica por intermédio dos novos conteúdos, métodos, espaços e atores pedagógicos, incorporando novas sistemáticas de avaliação" (p. 41).

Inventariando as produções de Machado, identifica-se que ela aborda as práticas educativas na educação profissional apresentando duas categorias gerais da didática, como os conteúdos e princípios metodológicos para o seu ensino.

Ao tratar do ensino médio integrado, Machado (2010) menciona que o currículo dessa etapa da educação básica é constituído por conteúdos gerais ou básicos e profissionais ou tecnológicos que, entretanto, não se encontram em polos opostos: "[...] esta diferenciação não pode, a rigor, ser tomada como absoluta ainda que haja especificidades que devem ser reconhecidas" (MACHADO, 2010, p. 2). Para a autora (2010), as principais contribuições dos conteúdos básicos para a formação dos sujeitos são: os fundamentos para uma concepção científica da vida, o desenvolvimento das faculdades cognitivas e capacidades, a autonomia e capacidade para a autoaprendizagem contínua e crítica, a criatividade, o espírito de inovação e disposições à versatilidade que os atuais processos produtivos requerem.

Por sua vez, a educação profissional tem, na tecnologia, seu foco fundamental, a qual Machado (2008, p. 16) define como a ciência transdisciplinar "das atividades humanas de produção, do uso dos objetos técnicos e dos fatos tecnológicos”, e que estuda o trabalho humano e suas relações com os processos técnicos. Os conhecimentos tecnológicos são referências obrigatórias ao exercício de atividades técnicas e de trabalho e não podem ser confundidos com saberes empíricos, mas com os quais esses se relacionam. 
Ela afirma não ser mais aceitável a crença que os "conteúdos considerados gerais não seriam profissionalizantes; isto porque uma sólida formação geral tem sido reconhecida não só como um requisito de qualificação profissional no atual mundo do trabalho, como, talvez, o mais importante" (MACHADO, 2008, p. 82).

No que concerne à metodologia, Machado (2010) defende propostas de ações didáticas integradas que relacionem esses conteúdos tipificados como diferenciados, pois, segundo a autora, "por razões didáticas, se divide e se separa o que está unido. Por razões didáticas, também se pode buscar a recomposição do todo. Tudo depende das escolhas entre alternativas de ênfases e dosagens das partes e das formas de relacioná-las" (p. 82). Ela sustenta a necessidade de o professor saber contextualizar esses conteúdos, o que envolve "[...] um processo de construção de conhecimentos, situado historicamente e socialmente, que provém e se desenvolve em íntima relação com a prática social" (p. 88) e ainda "dar centralidade à relação teoria e prática, integrar áreas de conhecimento e desenvolver as capacidades de observação, experimentação e raciocínio" (idem). Nesse sentido, reconhece que o processo educacional

[...] se transforme num processo investigativo, o qual inclui o planejamento, a colocação em prática de processos pedagógicos ordenados, lógicos e coerentes e a avaliação contínua. Qualquer que seja ele, este processo não se resume, porém, a procedimentos técnicos e a sistemas de instruções predefinidas aos quais cabem professores e alunos se adaptarem. Os conteúdos, métodos, processos, meios e técnicas pedagógicas estão subordinados às finalidades do processo educativo. Eles não são, portanto, um mero resultado da racionalidade do planejamento (MACHADO, 2010, p. 92).

Os espaços educativos de formação para o trabalho também são mencionados por Machado (2010), que advoga que a escola "precisa atuar com suas fronteiras ampliadas, pois os relacionamentos com o ambiente externo podem lhe proporcionar diversos benefícios. Sua estabilidade está também vinculada à sua inserção, relação e envolvimento com a realidade local e regional" (MACHADO, 2008, p. 91).

Explicitadas as categorias gerais da didática articuladas às práticas formativas da educação profissional expressas nos artigos analisados, a próxima seção está direcionada a identificar a emergência do debate acerca da elaboração de uma didática específica para essa modalidade de ensino.

\section{A didática da educação profissional como campo em construção}

A primeira dificuldade para elaborar uma possível didática para a educação profissional está ligada à resposta que é possível formular para a seguinte questão: que didática é requerida para qual educação profissional? 
Essa dificuldade está ligada ao fato que as opções que se faz para promover a formação dos trabalhadores - como a seleção dos conteúdos e metodologia de ensino, por exemplo -, não são neutras, mas reveladoras de um projeto político e de uma concepção de educação que se materializam por meio delas, já que, numa sociedade capitalista como a brasileira, segundo Ramos (2011, p. 45):

A formação da classe trabalhadora em suas dimensões tanto geral e cultural quanto específica para o exercício da vida produtiva, está no plano de disputa por hegemonia pelas classes burguesa e trabalhadora. Na perspectiva da primeira, a educação dos trabalhadores subsume-se à necessidade do capital em reproduzir a força de trabalho como mercadoria. Ao contrário, a classe trabalhadora disputa um projeto educativo que possibilite sua formação como dirigentes visando à superação de sua dominação pela classe antagônica.

Assim, vários autores apontam, na história da educação brasileira e profissional, a disputa entre dois projetos de educação profissional, que exemplificamos com o excerto de Araujo (2008, p. 55).

[...] o pragmático, que busca subordinar a educação aos interesses imediatos da realidade dada, e o de uma pedagogia da práxis, que se orienta para um tipo de formação comprometida com a construção de um futuro mais justo e que busca um modelo de formação que favoreça os processos de qualificação dos trabalhadores. Estes projetos se estruturam respectivamente sobre uma filosofia da educação com bases no pragmatismo e sobre os princípios da filosofia da práxis (Grifos nossos).

A existência desses dois projetos, na educação profissional, se materializa em pedagogias diferenciadas: de um lado, a formação pragmática de Roberto Mange, baseada no Taylorismo e na aplicação das séries metódicas de ensino e, posteriormente, como herdeira dessa tradição, a pedagogia das competências e, de outro lado, a educação politécnica ${ }^{2}$, termo esboçado, inicialmente, por Karl Marx, em meados do século XIX. Em torno dos dois projetos educacionais, gravitam duas possibilidades de construção da didática da educação profissional já que seus elementos constitutivos - finalidades/objetivos educacionais, conteúdos curriculares, métodos de ensino e avaliação - se estruturam de forma diversa, de acordo com projeto que o professor se propõe a efetivar.

Feita essa advertência, passa-se a analisar a pesquisa de Araujo (2010), que partiu da premissa da necessidade de elaboração de uma didática especial para ensinar os saberes profissionais, dada as suas especificidades. O projeto de pesquisa "As práticas formativas em educação profissional do estado do Pará: em busca de uma didática da educação profissional” (2010, p. 2), teve como propósito identificar a existência de uma didática da educação profissional e foi orientado, em síntese, por dois objetivos centrais: 
- Levantar, organizar e sistematizar a produção brasileira da área de trabalho e educação que reflita sobre propostas e estratégias formativas em educação profissional;

- Analisar as estratégias formativas de trabalhadores efetivadas nas instituições sediadas na Região Metropolitana de Belém.

Para a consecução do primeiro objetivo analisou os artigos publicados na Revista Trabalho e Educação, entre os anos 2000 a 2006, e o Boletim Técnico do SENAC (2000 a 2008), e em trabalhos apresentados nas reuniões da ANPED no período de 2000 a 2007 para neles identificar as características da didática da educação profissional. Foram elencados, como categorias de análise, os elementos constituintes da didática: finalidades, conteúdos, métodos de ensino e de avaliação da educação profissional que foram analisados a partir dos pressupostos do materialismo histórico. A pesquisa apontou, nos trabalhos analisados, a existência de duas concepções, a pragmática e a filosofia da práxis, que $\operatorname{Araujo~(2010,~p.~86,~p.~} 112$ e p. 156) chamou de Pedagogia do Capital e Pedagogia do Trabalho e, como exemplo, reproduzimos as suas conclusões quanto às finalidades da educação profissional:

O discurso da formação do cidadão produtivo, da educação para a empregabilidade e da referência fundamental no mercado se coloca enquanto elemento discursivo da perspectiva pragmática, enquanto o homem amplamente desenvolvido serve como principal referência para a pedagogia da práxis (ARAUJO, 2008, p. 56).

O segundo objetivo de Araujo (2010, p. 167) foi o de "identificar, na realidade paraense, elementos das práticas pedagógicas dos professores de diferentes instituições de educação profissional que permitissem uma caracterização (e posterior análise) acerca de uma didática da educação profissional”. Para tanto, entrevistou professores de quatro instituições de EP do Pará e os dados foram categorizados da mesma forma que os artigos. A conclusão também se repetiu, pois identificou finalidades/objetivos, conteúdos e métodos de ensino e de avaliação ligados aos dois projetos políticos. Araujo (2010, p. 208) conclui que: “[...] mesmo questões técnicas da didática são definidas, explicadas e entendidas em função dos projetos político-filosóficos aos quais elas se assentam e se articulam. Não há forma de ver a dimensão pedagógica dissociada da dimensão política”.

Também se buscou em Ramos (2014), indícios de existência de uma didática da educação profissional. Embora a autora não use essa denominação - seu objetivo é elucidar como a filosofia da práxis pode contribuir para a formação dos traba- 
lhadores na escola - afirma que o planejamento e execução da proposta pedagógica são orientados pelas perguntas: ensinar por quê? (finalidades/objetivos), o que? (conteúdos), como? (metodologia e avaliação), o que inclui os elementos constituintes da didática. Segundo ela, as respostas a essas indagações são divergentes em função do projeto político a que se está a serviço, mas ela toma como balizadora da formação de trabalhadores a filosofia da práxis e a pedagogia histórico-crítica e, a partir delas, aponta os princípios, finalidades, conteúdos e metodologias de ensino da educação profissional.

Quanto aos princípios, Ramos (2014) referencia o trabalho como princípio educativo, a formação omnilateral e a formação politécnica. Em relação às finalidades, defende que deveria ser a formação profissional politécnica, a escola unitária que, a princípio, não inclui a profissionalização. Entretanto, compreende ser essa uma necessidade conjuntural do Brasil e, por isso, argumenta que a adoção de uma política consistente de profissionalização no ensino médio “[...] desde que condicionada à concepção de integração entre trabalho, ciência e cultura, pode ser a travessia para a organização da educação brasileira com base no projeto de escola unitária, tendo o trabalho como princípio educativo" (RAMOS, 2014, p. 210).

No que concerne aos conteúdos e métodos da educação profissional, aponta os conhecimentos científicos e os de ordem ética e estética, que conformam o elemento cultural dos grupos sociais, traduzidos em teorias e conceitos. Porém, tomando como referência a dialética marxista, adverte que esses têm a totalidade como exigência metodológica, pois

[...] teorias, conceitos e fatos isolados são abstrações; são momentos arti $\square$ cialmente separados do todo. Eles só adquirem concreticidade quando inseridos no todo correspondente. Assim, o processo cognoscitivo da realidade é um movimento circular em que a investigação parte dos fatos e a ele retorna, num movimento de interpelação, interpretação, avaliação e crítica dos fatos. Os conteúdos de ensino são, portanto, conceitos explicativos de fenômenos e relações que constituem a totalidade concreta (RAMOS, 2014, p. 211).

Para a autora, o desafio metodológico é articular as particularidades - expressas nos processos produtivos objetos da formação pro $\square$ ssional - com a totalidade, que se refere às relações sociais próprias ao modo de produção capitalista. Ainda no campo metodológico, defende que os processos de ensino se baseiem na categoria da práxis, tomando o sujeito que aprende e as suas atividades como elementos centrais “[...] pela proposição de desafios, problemas e/ou projetos, desencadeando, por parte do aluno, ações resolutivas, incluídas as de pesquisa e estudo de situações, a elaboração de projetos de intervenção, dentre outros" (RAMOS, 2014, p. 213). 
Destarte, Barato $(2004,2008)$ procurou identificar a existência de uma didática para a educação profissional e sua abordagem é especificamente em relação ao ensino do saber técnico. Ele reporta a existência de uma tipologia de saberes fatos, conceitos, princípios e processos -, e defende que o ensino de cada um deles demanda formas diferenciadas de tratamento: os três primeiros podem ser ensinados no plano discursivo, enquanto os processos exigem demonstração. Para o autor, a didática utilizada na educação profissional ainda é acentuadamente semelhante à da educação geral, que dá conta satisfatoriamente do ensino de fatos, conceitos e princípios, mas não é adequada para o ensino de processos, que envolvem a execução de técnicas profissionais e, por isso, requerem tratamento didático específico.

Barato $(2004,2008)$ não faz referência às concepções e finalidades da educação profissional, mas aborda os conteúdos e métodos de ensino. No que concerne aos conteúdos, afirma que há a valorização do conhecimento científico, em detrimento do empírico, ou seja, a educação profissional desvaloriza os saberes constituídos no e pelo trabalho.

Barato (2008) trata dos métodos de ensino e, nesse sentido, aponta como problema central da didática da EP a falsa dicotomia teoria e prática, em que o saber técnico - que chama de "saber como" - é visto como prática e essa precisa estar fundada em teorias consistentes - o "saber que". Ele explica: "O saber como é constituído por processos de execução que dão fluência à ação. O saber que é constituído por proposições que explicam as coisas, define-as, estabelecem critérios de verdade. Cada uma dessas dimensões tem status epistemológico próprio" (BARATO, 2008, p. 9, grifos do autor). Via de regra, segundo ele, a teoria é ensinada por meio da linguagem, enquanto o aprendizado da prática se efetiva pela mediação do corpo, com explorações visuais e táteis. A concepção predominante na educação profissional é de que:

Teoria é verbo, explicação, discurso sistematizado. Qualquer experimentação, execução, manipulação está fora do jogo. Depois de bem assentada a teoria, supõe-se que os alunos estarão preparados para aplicá-la. E a aplicação constitui a prática, um fazer guiado pela teoria. Uma prática sem teorização prévia é um ato desprovido de inteligência. Em si mesmo, o fazer não é inteligente (BARATO, 2008, p. 8).

Entretanto, Barato (2004, p. 53) discorda dessa concepção por defender que teoria e prática são duas instâncias distintas: a prática não é a aplicação da teoria, o saber fazer, "saber como" exige processos cognitivos diferentes do "saber que": 
Ao que tudo indica, as aprendizagens que demandam execução engajam os aprendizes em modos de pensar necessários para que se constitua um conhecimento que represente o fazer. Falar e fazer [...] requerem diferentes formas de pensar. [...] o fazer demanda um conhecimento específico, próprio, em vez de ser aplicação de um conhecimento que dele pode ser desvinculado.

Para o autor, o reconhecimento dessas diferenças entre aprender a teoria e a prática tem implicações para o ensino porque:

[...] explicações bem estruturadas não são garantia de execuções fluentes e corretas. Estas últimas requerem uma aprendizagem própria, pois o saber que lhes é intrínseco não é aplicação da teoria, mas uma dimensão de conhecimento cuja base é um entendimento [geralmente não-verbal] da ação (BARATO, 2008, p. 10).

A exigência de competências operacionais básicas da profissão, portanto, ratifica a importância das aulas práticas em cursos técnicos, que tem como um dos seus objetivos o desenvolvimento de habilidades para o exercício de práticas profissionais. Por isso, Barato (2004), embora advirta que não se propõe a esmiuçar prescrições sobre como ensinar processos, apresenta uma sequência de passos para esse ensino: 1. Apresentação sintética do processo; 2. Análise de passos e operações; 3. Demonstração comentada; 4. Praticagem dos aprendizes; 5. Avaliação.

Ele reporta que esse procedimento não dispensa a "teoria" porque fatos, conceitos e princípios podem ajudar a realização do processo e são retomados na etapa da análise dos passos e operações. Em suas palavras: “[...] na aprendizagem de um processo (saber como) certas explicações relacionadas com ciência (saber que) podem clarear determinada decisão ou indicar o sentido de uma operação. Em muitas construções teóricas o fazer precede a teorização e é necessário para que ela ocorra" (BARATO, 2008, p. 9). Como se constata, o autor aponta indícios sobre a aprendizagem dos saberes técnicos, especialmente processos.

Por fim, analisamos os trabalhos de Gruber; Allain; Wollinger (2017) e Wollinger; Allain; Gruber (2017) que buscam identificar uma epistemologia da educação profissional, com base nos aportes teóricos da didática profissional francesa, para a criação de uma didática da educação profissional. Os autores, tomando como referência o trabalho de Pastré; Mayen; Vergnaud (2006), situam a gênese dessa corrente teórica na França na década de 1990 a partir da análise do trabalho e que tem por objetivo formar as competências profissionais, criando uma aproximação entre a formação profissional e a atividade de trabalho. Essa didática da educação profissional está apoiada nos princípios que norteiam a educação de adultos e em três correntes teóricas: a psicologia do desenvolvimento, a ergonomia cognitiva e a didática. 
No tocante à educação de adultos, a didática profissional francesa toma como referência a engenharia de formação, que segundo Pastré; Mayen; Vergnaud (2006, p. 2),

É um campo de práticas que consiste em construir dispositivos de formação correspondentes a necessidades identificadas para um dado público no âmbito de seu ambiente de trabalho. A formação escolar tende a descontextualizar as aprendizagens. A engenharia de formação vai insistir pelo contrário no contexto social no qual deve efetuar-se a aprendizagem de adultos em formação. Pois estes adultos são antes de mais nada pessoas que trabalham e, quando resolvem fazer uma formação, esta é habitualmente concebida com base no seu trabalho, e não a partir de recortes disciplinares, os quais geralmente fazem pouco sentido para eles.

A ergonomia cognitiva toma como referência Leplat (1997), a psicologia do desenvolvimento fundamenta-se nos trabalhos de Piaget e Vygotsky e na didática, toma como aporte teórico os estudos de Guy Brousseau e de Régine Douady.

Gruber; Allain; Wollinger (2017, p. 6) identificam três orientações que sustentam a didática profissional francesa:

1) a análise das aprendizagens não pode estar separada da análise da atividade dos atores, pois há uma continuidade profunda entre agir e aprender de e em sua atividade; 2) para analisar a formação das competências profissionais é preciso observá-las primeiro nos locais de trabalho; 3 ) vale a pena utilizar a teoria da conceituação na ação para compreender como se articulam atividade e aprendizagem num contexto de trabalho.

Essas orientações indicam a necessidade de ampliar os estudos acerca da natureza da aprendizagem no processo do trabalho cotidiano para, a partir dela, organizar as práticas educativas na educação profissional. Os autores ratificam o pensamento de Pastré (2002), que defende não ser possível formar um profissional sem antes recorrer à análise do trabalho e à compreensão da cognição do sujeito trabalhador. Esse parece ser o maior desafio para a elaboração da didática da educação profissional, pois como bem explicitou Oliveira (2015, não paginado)

O que nos falta muito é conhecer realmente o processo de trabalho, tal como ele ocorre nas áreas técnicas. Quer dizer, há pouco estudo sobre o trabalho cotidiano, por exemplo, saber como o mecânico, o eletricista, a pessoa que trabalha com a informática, como ocorre a relação desse sujeito com o objeto de conhecimento e de trabalho dele. Não há estudos sobre como o sujeito aprende determinada atividade relativa a uma área técnica propriamente dita, sobre essa construção do conhecimento do profissional na prática nas áreas técnicas. Então, a forma como o professor acaba trabalhando em sala de aula é de dizer assim: "faz primeiro isso, depois isso, depois isso". O que ele faz? Ele passa a ensinar as etapas que ele cumpre lá na atividade prática. Passa a ensinar para os seus alunos isso. Então entendo que quando essas pesquisas - acho que a gente tem que incentivar pesquisas mesmo -, passarem a ter um corpo mais denso, isso vai nos ajudar na docência da educação profissional. 
Tomando como referência as categorias da didática, a exemplo do que se buscou nos demais trabalhos analisados, partiu-se da explicitação do conteúdo da educação profissional. Gruber; Allain; Wollinger (2017) partem do pressuposto que a educação profissional se distingue dos demais níveis e modalidades de ensino porque trata da formação para o trabalho e essa, por sua vez, se relaciona ao exercício social da técnica. A concepção de técnica é tomada de forma mais alargada que o domínio de um saber fazer, mas como [...] uma intervenção humana no mundo para produzir a sua existência. Essa produção da existência refere-se tanto às suas condições materiais de vida de ser humano, quanto à constituição de seu ser social, cultural, identitário, entre outras dimensões envolvidas no Trabalho (GRUBER; ALLAIN; WOLLINGER, 2017, p. 4).

Segundo os autores, é ingênuo pensar o conhecimento técnico da educação profissional como aplicação do conhecimento teórico, de que a tecnologia é a aplicação da ciência. Eles exemplificam essa posição:

As técnicas da eletrotécnica, enfermagem, química, radiologia, etc., envolvem saberes, habilidades, atitudes e valores que podem ter (ou não) origem nas disciplinas científicas, mas que se constituem numa área técnica, numa tradição ou corporação profissional. As técnicas se conectam e se apoiam em conhecimentos científicos diversos, tanto das chamadas ciências "exatas" como das "humanas", mas suas especificidades extrapolam as ciências. Sua riqueza aparece nos currículos de cursos técnicos e resiste à crença em uma formação científica genérica que as englobaria (WOLLINGER; ALLAIN; GRUBER, 2017, p. 10).

Citando Tourmen et al. (2017, p. 18 apud WOLLINGER; ALLAIN; GRUBER, 2017, p. 9), os autores analisados concluem que "conhecimento e ação interagem: a ação não é vista como uma aplicação do conhecimento formal, nem como separada dele. Não existe ação sem conceitos, e os conceitos são construídos e usados em ação."

Do ponto de vista metodológico, essa ideia implica na compreensão de que a didática de educação profissional tem por objeto o processo de intervenção e exercício social do educando., como afirma os autores, "[...] tanto no que diz respeito ao planejamento, às estratégias de ensino ou à avaliação, o conhecimento verbal/ teórico deixa de ser o centro das atenções e passa a ser elemento do processo" (GRUBER; ALLAIN; WOLLINGER, 2017, p. 5). É a reflexão orientada pela ação sobre o mundo e, mais objetivamente, sobre os processos e técnicas que, na educação profissional, não se esgota no plano discursivo. 


\section{Considerações finais}

O propósito deste trabalho foi identificar como autores referenciais da área da educação profissional apresentam a discussão acerca da didática para essa modalidade de ensino e como têm caracterizado as práticas formativas, em suas produções acadêmicas, que nela são desenvolvidas. Assim, ao analisar os trabalhos dos autores identificou-se que Ramos (2011) e Araujo (2008) apontam para a existência de duas pedagogias que representam posições diferenciadas quanto às finalidades da educação profissional: a pedagogia pragmática e a educação politécnica. Assim, tão importante quanto explicitar o que caracteriza essa didática é compreender a que/quem ela se destina.

Quando tratam da didática na educação profissional, Kuenzer (1998, 2010) e Machado $(2008,2010)$ apontam os seus elementos centrais, como os conteúdos, as formas metodológicas, o espaço educativo e a avaliação. Defensoras do ensino técnico integrado ao ensino médio, as autoras reafirmam a importância desses elementos para a formação geral dos educandos, articulando-os às exigências para a formação profissional.

Dentre os autores referenciais que tratam de forma mais específica a didática da educação profissional estão Ramos (2011, 2014), Barato (2004, 2008), Araujo (2008, 2010) Gruber, Allain; Wollinger (2017) e Wollinger; Allain; Gruber, (2017) que procuram explicitar os elementos que podem constituir uma didática específica para a educação profissional.

Embora os trabalhos analisados demonstrem a necessidade de elaboração de uma didática específica para a educação profissional - posto que ela se diferencia dos demais níveis e modalidade de ensino - e apontem elementos significativos para a sua constituição, não se pode advogar a sua existência, já que faltam pesquisas que, incidindo sobre os processos de produção e de aprendizagem dos saberes técnicos, especialmente dos processos operacionais, subsidiem a formulação de proposições para elaboração dessa didática. Esse é um tema que pode constituir novos estudos nesta área.

\section{Notas}

1 Referimo-nos a saber escolar na perspectiva apontada por Chevallard (1998) que identificou três tipos de saberes: saber sábio (ou de referência ou científico), o banalizado (do cotidiano) e o ensinável (o escolar). O primeiro é elaborado pelo grupo dos especialistas que, por meio da investigação, procura respostas para problemas concretos. Mas esse saber não pode ser transposto para o currículo escolar com as mesmas ca- 
racterísticas com que foi produzido, ou seja, precisa ser transformado para tornar-se saber ensinável que, por sua vez, não pode se reduzir a versões simplificadas do conhecimento científico, que lhe deu origem e transferidas para a sala de aula. Ele deve manter certa semelhança com o original, mas adquire significado diverso de acordo com o contexto escolar no qual será ensinado. Para tornar-se objeto de ensino, portanto, o saber sábio precisa ser deslocado do seu contexto de produção, simplificado, fragmentado em unidades de estudo que comporão o currículo e que serão ensinadas num tempo pré-determinado, o tempo escolar.

2 Tomamos como referência Saviani (2007, p. 10) para quem "Politecnia significa, aqui, especialização como domínio dos fundamentos científicos das diferentes técnicas utilizadas na produção moderna”. A educação politécnica, portanto, refere-se àquela que se contrapõe à formação profissional como adestramento, preparação para o desempenho de determinadas funções ou atividades sem a compreensão dos fundamentos dessas atividades e sua relação com o mundo do trabalho.

\section{Referências}

ARAUJO, R. M. L. Formação de docentes para a educação profissional e tecnológica: por uma pedagogia integradora da educação profissional. Trabalho \& Educação, Belo Horizonte, v. 17, p. 53-64, 2008.

ARAUJO, R. M. L. As práticas formativas em educação profissional no estado do Pará: em busca de uma didática da educação profissional. Relatório final. Universidade Federal do Pará, 2010. Disponível em: http://www.ufpa.br/ce/gepte/imagens/pesquisas_concluida/relatorio\%20 cnpq\%20didatica\%20de\%20ep\%20final.pdf. Acesso em: 15 nov. 2015.

BARATO, J. N. Em busca de uma didática para o saber técnico. Boletim Técnico do Senac, Rio de Janeiro, v.30, n.3, p. 46-55, set./dez. 2004.

BARATO, J. N. Conhecimento, trabalho e obra: uma proposta metodológica para educação profissional. Boletim Técnico do Senac, Rio de Janeiro, v. 34, n. 3, p. 4-15, set./dez. 2008.

CHEVALLARD, Y. La transposición didáctica: del saber sábio al saber enseñado. Tradução de Cláudia Gilman. 3.ed. Buenos Aires: Aique Grupo Editor S. A., 1998.

FERRETI, C. J. Educação profissional. In: OLIVEIRA, D.A; DUARTE, A.C.M.; VIEIRA, L. M. F. Dicionário: trabalho, profissão e condição docente. Belo Horizonte: UFMG/Faculdade de Educação, 2010. CD-ROM.

GRUBER; C; ALLAIN, O; WOLLINGER, P. R. Contribuições da didática profissional francesa para a educação profissional. 2017. V Seminário Nacional de Educação Profissional e Tecnológica - Senept. Belo Horizonte, Cefet-MG, 2017. Disponível em: https:/www.researchgate.net/ publication/317167758_Contribuicoes_da_Didatica_Profissional_Francesa_para_a_Educacao_ Profissional. Acesso em: 22 jun. 2018.

JUK, J. A didática na educação profissional técnica de nível médio no Instituto Federal do Paraná. Disponível em: educere.bruc.com.br/arquivo/pdf2017/26086_13282.pdf.

KUENZER, A. Z. Competência como práxis: os dilemas da relação entre teoria e prática na educação dos trabalhadores. Boletim Técnico do Senac, Rio de Janeiro, v. 29, n.1, p. 17-27, jan./ abr. 1998. 
KUENZER, A. Z. As mudanças no mundo do trabalho e a educação: novos desafios para a gestão. In: FERREIRA, N.S.C. (org.). Gestão democrática da educação: atuais tendências, novos desafios para a gestão. São Paulo: Cortez, 1995, v. 1, p. 33-57

KUENZER, A. Z. As relações entre conhecimento tácito e conhecimento científico a partir da base microeletrônica: primeiras aproximações. Educar em Revista, n. esp, p. 13-33, 2003.

KUENZER, A. Z. A articulação entre conhecimento tácito e inovação tecnológica: a função mediadora da educação. Rev. Bras. Educ. v.12, n. 36, p. 462 -473, 2007.

KUENZER, A. Z. Formação de professores para a educação profissional e tecnológica. In: DALBEN, A. L.; DINIZ, J.; LEAL, L.; SANTOS, L. (org.). Coleção Didática e Prática de Ensino. Belo Horizonte, Autêntica, 2010, p. 497-518. Disponível em: http://www.academia.edu/4894113/Colecao_didatica_e_pratica_de_ensino_-_Livro_3_PDF. Acesso em: 10 jun. 2014.

LIBÂNEO, J. C. Didática. São Paulo: Cortez, 1994.

MACHADO, L. R. S. Diferenciais inovadores na formação de professores para a educação profissional. Revista Brasileira da Educação Profissional e Tecnológica, v. 1, p. 8-22, 2008.

MACHADO, L. R. S. Ensino médio e técnico com currículos integrados: propostas de ação didática para uma relação não fantasiosa. In: MOLL, J. (org.). Educação profissional e tecnológica no Brasil contemporâneo: desafios, tensões e possibilidades. Porto Alegre: Artmed, 2010, p. 80-95.

OLIVEIRA, M. R. S. N. Entrevista realizada em 2015 no III Colóquio Nacional a Produção do Conhecimento em Educação Profissional. IFRN - Natal (RN) acerca da didática da educação profissional.

PASTRÉ, P; MAYEN, P.; VERGNAUD, G. La didactique professionnelle. Revue Française de Pédagogie, [s.l.], n. 154, p.145-198, 1 mar. 2006. OpenEdition. Disponível em: http://dx.doi. org/10.4000/rfp.157. Tradução do original realizada por GRUBER, C.; ALLAIN, O.

PIMENTA, S.G. Didática, didáticas específicas e formação de professores: construindo saberes. In: TIBALLI, E. F. A.; CHAVES, S. M. (org.). Concepções e práticas em formação de professores: diferentes olhares. Rio de Janeiro: D\&P, 2003, p. 49-56.

RAMOS, M. N. Referências formativas sobre práticas em educação profissional: a perspectiva histórico-crítica como contra-hegemonia às novas pedagogias. In: ARAÚJO, R. M. L.; RODRIGUES, D. S. (org.). Filosofia da práxis e didática da educação profissional. Campinas: Autores Associados, 2011, p. 45-66.

RAMOS, M. N. Filosofia da práxis e práticas pedagógicas de formação de trabalhadores. Trabalho \& Educação, Belo Horizonte, v. 23, p. 207-218, 2014.

SAVIANI, D. Trabalho e educação: fundamentos ontológicos e históricos. Rev. Bras. Educ., v. 12, n. 34, p. 152-165, jan./abr. 2007.

WOLLINGER, P. R; ALLAIN, O; GRUBER; C. Por uma nova formação docente na educação profissional. 2017. V Seminário Nacional de Educação Profissional e Tecnológica - Senept. Belo Horizonte, Cefet-MG, 2017. Disponível em: https://www.researchgate.net/publication/317167692_Por_uma_nova_formacao_docente_na_Educacao_Profissional. Acesso em: 22 jun. 2018. 